\title{
O match entre o amor e o mercado: uma análise antropológica das masculinidades em aplicativos de relacionamento*
}

Fernando de Figueiredo Balieiro**

O roteiro do flerte tem se transformado desde o advento da era digital. A segunda metade dos anos 90 foi marcada pela emergência das salas de bate-papo e dos sítios de relacionamento, nos quais a descrição textual de si era a forma predominante de apresentação em um contexto de relativo anonimato. Os pretendentes possuíam escassos recursos de imagem e de som, deixando ao encontro pessoal o conhecimento integral e sensível de seus possíveis parceiros. O início do século XXI testemunhou avanços tecnológicos como a emergência das webcams, máquinas fotográficas digitais, escâneres à conexão de banda larga, em uma internet cada vez mais dominada pelas redes sociais. Na década seguinte, houve a disseminação dos telefones inteligentes com câmera acoplada, os quais passaram a operar quase como uma extensão do corpo.

A selfie tornou-se manifestação síntese de uma característica que, segundo lara Beleli (2015), se impôs de maneira definitiva: o imperativo das imagens. O novo cenário de abundância das fotografias pessoais possibilitou a racionalização detalhista dos códigos transmitidos pelas imagens e o uso disseminado de filtros de edição, ambos elementos estratégicos na busca amorosa e sexual. Além das imagens, os aplicativos de relacionamento inovaram com recursos sociotécnicos para escolha e comunicação entre possíveis pretendentes, como o próprio recurso do match, o qual viabiliza o encontro entre duas pessoas, sem que nenhuma se exponha à recusa do outro. É sobre a dinâmica das relações nos aplicativos que Larissa Pelúcio se debruça, propondo um ângulo inovador de análise das relações de gênero na sociedade contemporânea, em um rico campo de pesquisa que intersecciona as temáticas da masculinidade contemporânea, a emergência dos aplicativos de relacionamento $e$ as novas configurações do amor.

A leitura de Amor em tempos de aplicativos é um mergulho na escrita etnográfica da autora que, logo de início, informa aos leitores que nunca fora tão nativa. A pesquisa impôs à autora experienciar a lógica das emoções e ansiedades próprias dos aplicativos que pesquisou. Seu campo abarcou um elemento-chave da etnografia para a internet, tal como afirma Christine Hine (2015), uma intensa reflexividade sobre os usos das tecnologias pela própria investigadora. A análise se ancorou na própria experiência vivida e refletida da pesquisadora sobre as demandas emocionais do uso dos aplicativos $e$ as relações estabelecidas com seus interlocutores. A abundância dos contatos, as demoras nas respostas, as recusas, as investidas, as cobranças, as ofensas foram a matéria-prima para a compreensão da autora do universo de análise.

O mergulho no campo foi expansivo e profundo, abarcou quase 330 homens em seu questionário inicial. Seguiu-se a observação acompanhante de interlocutores de quem se aproximou, além de dezenas de conversas iniciais, "negociações", que ofereceram rico material para reflexão. A extensão dos interlocutores permitiu o foco em três gerações de homens. A autora navega no mundo dos nascidos entre 1956 e 1965, os quais só conheceram a internet adultos, os

\footnotetext{
* Recebida em 10 de março de 2020, aceita em 09 de abril de 2020. Resenha do livro: PELÚCIO, Larissa. Amor em tempos de aplicativos: Masculinidades heterossexuais e a nova economia do desejo. São Paulo, Annablume, 2019.

** Professor Ajdunto do Departamento e Programa de Pós-Graduação em Ciências Sociaisa da UFSM, Santa Maria, RS, Brasil. fernandofbalieiro@gmail.com / https://orcid.org/0000-0003-3952-4779
} 
nascidos entre 1966 e 1975, aqueles que já eram jovens adultos quando se disseminou o uso da internet e os da casa dos 30 anos cuja socialização já seu de forma amplamente marcada pela presença da internet.

Pelúcio aborda o entrelaçamento entre as mudanças no amor contemporâneo $e$ as novas tecnologias. Os novos roteiros amorosos se entrelaçam com uma gramática tecnológica, incorporando a terminologia oriunda da língua inglesa: crush, match, ghosting e block são alguns dos termos correntes que dizem muito sobre a nova forma de se relacionar. São expressões, na acepção da autora, de seres desejantes de uma nova economia afetiva marcada por um regime de flexibilidade amorosa. Em uma era da abundância das escolhas sexuais providas pelos aplicativos de relacionamento, resta aos seus usuários gerir suas escolhas, se diferenciar $e$ inovar constantemente, tal como empreendedores em um mercado de afetos.

O livro estabelece diálogo privilegiado com a obra de Eva Illouz. A socióloga marroquina analisa a forma como o ideal de amor romântico vem sendo tensionado pela hegemonia do que chama de "sexualidade recreativa", deslocando a organização do sexo do matrimônio para o mercado de consumo, trazendo uma série de ansiedades e dilemas próprios da forma contemporânea de experienciar a vida amorosa e sexual. A internet potencializou uma de suas características, o sexo acumulativo, entendido na análise Pelúcio como elemento imprescindível para o exercício da masculinidade contemporânea. Para Illouz (2014) uma das utopias emocionais do presente é a conciliação entre os valores contemporâneos de liberdade e autonomia do sujeito com a promessa de doação ao outro em uma vida a dois. O imperativo da busca por excitação encontra seus limites e contradições na demanda por amor em parceria.

Em interlocução com Richard Miskolci (2017), Larissa Pelúcio prefere conceituar a paisagem emocional como a "nova economia do desejo" em contraponto à noção de uma "sexualidade recreativa", uma visão que poderia desqualificar a nova forma de lidar com a sexualidade, além de idealizar formas anteriores. A "nova economia do desejo" apresenta uma visão sócio-histórica da organização do amor e do desejo no presente, implicando em sua relação com transformações estruturais da sociedade, sua íntima associação com o mundo do trabalho forjado no século XXI $e$ as imbricações entre a subjetividade e o campo dos afetos com as dinâmicas contemporâneas do mercado.

No primeiro capítulo do livro, "Tudo o que é sólido desmancha no ar, tudo" - até a metodologia?, adentramos no campo da investigadora, nos percursos de sua etnografia multissituada que caminha dos sítios de encontro e aplicativos ao WhatsApp. Apresenta três aspectos cruciais da análise desenvolvida no decorrer do livro. Em um primeiro momento, recupera o argumento de Miskolci (2017) e Beleli (2015) do papel que as novas tecnologias desempenham ao oferecer a sujeitos subalternos, como mulheres $e$ homossexuais, maior controle na agência $e$ negociação moral. No entanto, a agência desejante dos atores sociais se faz mediada por uma arquitetura digital que preza pela velocidade, evocando emoções associadas à fluidez das relações contemporâneas.

Nas palavras da autora "são mídias ansiosas e impacientes, melhor dizendo, nos provocam facilmente essas emoções" (p. 46). Além de emocionais, as novas mídias são comerciais, é pela mecânica da escolha e do descarte, comum aos aplicativos de busca amorosa, que os sujeitos se adequam às novas formas de roteirizar o amor. À semelhança de catálogo de produtos em um mercado de pretendentes amorosos e sexuais, soma-se a segmentação da própria plataforma que visibiliza e invisibiliza possíveis parceiros a partir de critérios estabelecidos como a idade, a orientação sexual e a geolocalização.

A sensação de abundância induz à percepção de um universo infinito de escolha, mas também abre a consciência da alta concorrência neste mercado de afetos. Os aplicativos dão espaço aos empreendedores do amor e do sexo, buscando a construção de um "eu virtual" competitivo. A socialidade digital assim emula o mundo do trabalho contemporâneo, afeito a uma racionalidade neoliberal espraiada (conf. Dardot; Laval, 2016), mas a busca amorosa também está

\footnotetext{
1 Crush diz respeito ao pretendente amoroso, o match é o mecanismo que sinaliza o interesse mútuo dos usuários nos aplicativos, já ghosting é o ato de desaparecimento súbito e o block, o bloqueio de usuário, impedindo-o de continuar em contato.
} 
imbricada em termos práticos a ele. Segundo a antropóloga, "vários interlocutores, borrando as fronteiras trabalho/lazer, se distraiam em conversas picantes ou estimulantes durante turnos de trabalhos entediantes, sem se importarem com hipotéticos encontros fora dos meios digitais" (p. $60)$.

O segundo capítulo, $O$ político e o pessoal: masculinidades desafiadas, adentra nas problemáticas dos conflitos do presente e suas implicações nas relações amorosas, as quais inevitavelmente entrelaçam o pessoal com o político. Os interlocutores da pesquisa vivem um momento de tensões em um país em ebulição política. De um lado, representam homens desafiados pelas demandas de um feminismo ascendente. De outro lado, acompanham o reforço de visões reativas e pejorativas a respeito do feminismo. Ambos os aspectos são percebidos no contato da investigadora com os pesquisados, os quais buscam discursivamente se afastar da pecha de machistas, mas não raro - em suas práticas - reforçam as desigualdades e reafirmam certas visões desqualificadoras em relação às mulheres.

Novos modelos de masculinidade habitam o cenário fluido e contraditório das representações de gênero disponíveis. Um dos exemplos é o modelo do "homem sensível", representativo de certo capital simbólico que serve à distinção social no mercado das masculinidades. Não sendo necessariamente aquele que se compromete com o feminismo, representa um tipo que, ao menos em parte dos casos, se apropria de algumas de suas pautas para ser bem sucedido no mercado sexual. Outros homens, mais descapitalizados, concorrem no mesmo mercado, reforçando modelos mais tradicionais, os quais foram notados no trato não respeitoso com as mulheres, o que respingou na própria relação com a pesquisadora em um campo de pesquisa nem sempre acolhedor.

O capítulo três, Masculinidades ponto com, adentra na flexibilidade amorosa imposta pelo amor mediado pelos aplicativos, mais sentida pelos interlocutores com mais idade, mas não despercebida pelos mais jovens. O ethos da flexibilidade, também incorporado pela investigadora em sua prática etnográfica, reproduz características do mundo do trabalho, como a fluidez e informalização nas relações. E, sobretudo, emula um mercado competitivo que repassa ao indivíduo a incumbência de sobreviver diante do cenário de escassez. O romance aparece então como um empreendimento neoliberal, onde se deve otimizar, investir e negociar constantemente.

A nova economia sexual não apenas deriva da nova racionalidade econômica dos tempos atuais, ela têm suas origens nas mudanças políticas e culturais promovidas desde os anos 1960 pela revolução sexual e, em especial, pelo feminismo. A satisfação sexual e a erotização dos corpos, também promovida pelas mídias em ascensão, acompanha a crítica às convenções morais dos movimentos contestadores, bem como o repúdio a hierarquias que reduziam à mulher às figuras da santa e da puta. As transformações certamente promoveram maior simetria entre os gêneros, mas também reconfiguraram certas assimetrias.

A desigualdade na vida sexual entre homens e mulheres, por exemplo, pode ser percebida quando a fruição flexível do sexo representa sempre um reforço do status masculino, ao mesmo tempo em que a flexibilidade sexual feminina é recorrentemente avaliada em tons negativos para mulheres. Para eles, as "transas" seriais se revertem em capital erótico, enquanto que para elas não se dá o mesmo. Esse é um dos traços que caracterizam o que a autora empresta de lllouz para compreender o que chama de "dominação emocional", ou seja, o controle da relação por parte dos homens em um enquadramento sociocultural que garante a eles maior desprendimento emocional $e$ menores cobranças em relação a seu não comprometimento em relações duradouras.

A desigualdade de gênero é observada na recorrência de juízos de valor em tom de superioridade moral por parte dos homens. A qualificação das mulheres como "complicadas" ou "loucas" aparece como resposta aos desencontros amorosos nos aplicativos. Em especial, em situações de definição imprecisa das interações, próprias do mundo digital, que alcançam a intimidade quando ainda não há relação estabelecida. Outra qualificação concorrente é a das "mulheres resolvidas", categoria à qual muitos interlocutores compreenderam a própria investigadora. Associada à experiência, maturidade, iniciativa e independência financeira, elas evocam tanto a admiração desejante, como o medo e a recusa. Em especial quando se salienta sua agência desejante, o que gera incômodo, posto que parece subverter a ordem dos gêneros, na medida em que a masculinidade contemporânea requer autonomia e autoridade no campo sexual. 
O quarto capítulo, Amor (?) em tempos de aplicativos, aprofunda sua abordagem das mudanças na paisagem emocional do presente. Em seu diagnóstico, vivenciamos a era do "laissefaire" romântico, sintetizada na expressão corrente do "estamos deixando rolar", o slogan dos amores neoliberais. A nova racionalidade neoliberal impôs um novo ethos relacional, um ethos que passa pela não pactuação dos termos da relação, dando origens a recorrentes desencontros $e$ reforçando assimetrias. O cenário é de "precarização das relações amorosas", expressão de uma época que reforça o imperativo da busca constante por novas possibilidades amorosas $e$ sexuais $e$ enfraquece a possibilidade de construção de parcerias igualitárias.

No presente, a masculinidade passa a ser reelaborada a partir da relação entre risco $e$ investimento, no caso, de tempo e de recursos emocionais. Investir, arriscar e acumular parece mais afeito ao mundo da masculinidade do que o universo privado do comprometimento afetivo, o qual potencialmente emascularia os homens. Não se trata de uma questão resolvida para os homens, interlocutores de sua pesquisa. Pelo contrário, a antropóloga notou a vívida contradição entre expectativas em tensão, entre a constituição de vínculos sólidos e incitação ao acúmulo de experiências sexuais. Essas tensões são experenciadas de forma diferente, de acordo com as idades e gerações, sendo ainda mais acentuadas entre os mais jovens.

A conclusão da autora é que os binarismos convencionais cedem espaço para um cenário de novas configurações relacionais também opressivas. No seu campo de pesquisa, os homens não demonstraram disposição em rever radicalmente as assimetrias de gênero. O amor nos tempos de aplicativos reforça o regime heteronormativo contemporâneo que, nas palavras da autora "tem dificultado o match entre homens e mulheres e, por outro lado, favorecido o crush entre amor $e$ mercado" (p. 219).

Finalmente deu match, as considerações finais da autora, tocam na relação entre o questionado amor das buscas dos aplicativos e o contexto sociopolítico de inflexão feminista pelo qual o Brasil passou nas últimas décadas. As contradições e dilemas de seu campo parecem de alguma forma refletir o universo conflituoso da vida política nacional recente, com a emergência de forças políticas reativas às conquistas das mulheres.

Sua pesquisa, fruto de rica etnografia, permitiu articular, com sofisticação, uma abordagem focada das relações afetivas contemporâneas, passando pela análise crítica das dimensões mercadológicas dos aplicativos, mediadora dos encontros, e da realidade econômica e sociopolítica que subjaz a eles. A descrição e análise em profundidade do universo dos interlocutores de seu campo não isentou a autora de tecer relações com questões abrangentes de mudança social de nosso tempo. Ao contrário, sua perspectiva permite entrelaçar questões subjetivas e emocionais com alterações de amplo escopo do universo econômico e político do presente. Amor em tempos de aplicativo é uma contribuição ímpar aos estudos de gênero e sexualidade, como também às emergentes Sociologia e Antropologia digital.

\section{Referências bibliográficas}

BELELI, lara. O imperativo das imagens: construção de afinidades nas mídias digitais. cadernos pagu (44), Campinas, SP, Núcleo de Estudos de Gênero-Pagu/Unicamp, 2015, pp.91-114. ISSN 1809-4449 [https://periodicos.sbu.unicamp.br/ojs/index.php/cadpagu/article/view/8637321 - acesso em 15 de junho de 2021].

DARDOT, Pierre; LAVAL, Christian. A nova razão do mundo: ensaio sobre a sociedade neoliberal. São Paulo, Boitempo, 2016.

HINE, Christine. Ethnography for the Internet: Embedded, Embodied and Everyday. Bloomsbury, Londres, 2015.

ILLOUZ, Eva. Erotismo de autoayuda: cincuenta sombras de Grey y el nuevo orden romântico. Buenos Aires, Katz Editores, 2014.

MISKOLCI, Richard. Desejos digitais: uma análise sociológica da busca por parceiros on-line. Belo Horizonte, Autêntica Editora, 2017. 